\title{
Research on targeted land poverty alleviation patterns based on the precise identification of dominant factors of rural poverty: a case study of Siyang County, Jiangsu Province, China
}

\author{
Min $\operatorname{Min}^{1,2} \cdot$ Chen $\operatorname{Lin}^{1} \mathbb{D} \cdot$ Xuejun Duan ${ }^{1} \cdot$ Zhifeng Jin $^{3,4} \cdot$ Luocheng Zhang $^{1}$
}

Received: 1 July 2019 / Accepted: 21 December 2020 / Published online: 4 January 2021

(C) The Author(s) 2021

\begin{abstract}
Poverty is a common problem faced by various social and economic forms. Eliminating poverty is a major issue of common concern and research all over the world. Land policies for poverty alleviation are an effective means of affecting land agriculture development, increasing the productivity of cultivated land, and promoting growth in farmers' income and production. In recent years, it has played an important role in promoting poverty alleviation in poverty-stricken areas. However, the poverty alleviation needs of township units have not been precisely identified, and one-size-fits-all land policies are unable to effectively allocate poverty alleviation resources. Consequently, the actual efficiency of policies has been severely restricted, leading to regional differences in poverty alleviation. In response to this bottleneck, this study takes Siyang County in Jiangsu Province as a case study and adopts the geographical detector model to diagnose and identify the spatial differentiation characteristics and dominant factors of poverty and in various townships. The results can be summarised as 'four dominant factors of poverty-four regional types of poverty townships - four targeted land poverty alleviation patterns'. Detailed results are as follows: the dominant factors affecting differentiation of rural poverty in Siyang County are labour, technology, land resources, and financial support. The various townships of the county were thus classified into four types according to the main factor affecting poverty: labour-constrained, land-constrained, capital-constrained, and technique-constrained, and proposed four targeted land poverty alleviation patterns for the different constraint types and then to improve the effectiveness of land development policies to successfully achieve precise poverty alleviation and reinforce strategies revitalising rural communities.
\end{abstract}

Keywords Rural poverty · Dominant factors · Precise identification · Geographical detector $\cdot$ Land poverty alleviation patterns $\cdot$ Siyang County

Chen Lin

clin@niglas.ac.cn

Extended author information available on the last page of the article 


\section{Introduction}

Poverty is a common problem faced by various social and economic forms (Carr et al. 2014; Haushofer and Fehr 2014; Mani et al. 2013; Sen 1999). And it is still a major issue of common concern and research all over the world (Shepherd 2010; Li et al. 2019; Liu and Li 2017). Among them, rural poverty is a serious social problem caused by the urban-rural dual structure, which has become the main limiting factor affecting the coordinated development of urban and rural areas (North 1955; Liu et al. 2015; Long et al. 2009; Wang et al. 2016a, 2016b). Following the reform and opening up, the Chinese governmentinitiated policies of large-scale poverty alleviation ( $\mathrm{Li}$ et al. 2015a, 2015b). The rural poor population in China dropped from 250 million in 1978 to 30.46 million at the end of 2017, and poverty incidence rate has been reduced by $28.51 \%$ (National Bureau of Statistics 2018). China has also contributed significantly to the global anti-poverty campaign. However, the country's remaining 30 million poor people (National Bureau of Statistics 2018), who have the poorest foundation and face the worst conditions, are considered the most difficult obstacle in poverty alleviation (Wang et al. 2016a, 2016b; Liu et al. 2017). Currently, China still faces the arduous task of poverty management and has not yet fundamentally resolved the problem of lagging development in poverty-stricken areas (Liu et al. 2017; Liu and Li 2017). In addition to the existing measures, the state must urgently implement innovative ideas and methods for poverty alleviation and development (Berger et al. 2018; Jean et al. 2016), deeply and accurately tap the poverty driving factors in poor areas, and must explore new models of precise poverty alleviation that consider rural development in poverty-stricken areas and the practical needs of farmers.

In order to escape from poverty, countries around the world have carried out various forms of poverty reduction actions: Britain has formed a poverty alleviation system centred on the poverty relief law (Kelly and Gráda 2010) and a welfare state system characterised by high welfare (Gourvish and Fraser 1973), and India has launched the land revolution (Besley and Burgess 2000) and the green revolution (Iari 1970). With the in-depth development of poverty reduction actions, human understanding of poverty has been constantly enriched and extended. Amartya Sen put forward the multi-dimensional poverty view based on ability poverty and right poverty (Sen 1999), which provides a footnote of academic history for the development of precise poverty alleviation theory in the theoretical analysis of the causes of poverty and the ways of poverty alleviation (Yue and He 2016). In recent years, some scholars have introduced space into the study of multi-dimensional poverty and have formed a more influential 'space poverty' theory. It synthesises a series of economic, social, and environmental indicators into geographical capital. By studying the spatial agglomeration characteristics and rules of geographical capital and expressing them in the form of poverty map, it determines whether there is a spatial poverty trap, and a poverty reduction strategy is designed accordingly (Gobillon and Selod 2014). This theory highlights the 'spatial attribute' of poverty problem and takes the coupling process and state of regional 'people-industry-land' as the evaluation standard of poverty identification, which provides a new idea for the practice of precise poverty alleviation.

Land is the most important 'dormant' resource, asset, and capital in poverty-stricken areas and is thus the foundation for economic development and poverty alleviation in these regions (Yan 2017; Dong 2004; Wu et al. 2005). The vast rural poor areas of China are generally facing a series of problems such as extensive land use, insufficient input of agricultural production materials, and difficulties in rural land transfer (Long et al. 2016a, 2016b). Lack of land resources and low utilisation efficiency have become one of the 
major bottlenecks restricting economic and social development in rural areas (Zang et al. 2019). Land poverty alleviation policies, as important ways to supplement cultivated land, revitalise existing land, optimise urban and rural land, intensive land use, improve land productivity (Long 2014; Zhou et al. 2018), have a positive effect on promoting regional poverty reduction and development, and are regarded as a 'golden key' (Yan 2017; Zhou et al. 2018). Developed countries and regions have adopted land poverty alleviation policies as an important way to adjust the 'people-industry-land' relationship and increase farmers' income. By establishing a land remediation system with the goal of multiple land use in Bavaria, Germany, while promoting agricultural development and increasing farmers' income, it has protected rural culture and traditional landscapes and achieved comprehensive rural development ( $\mathrm{Bi}$ et al. 2012). Land remediation in the Netherlands has created a lot of employment opportunities for local farmers (Liao and Du 2014). This has been further confirmed by numerous studies on the use of land for poverty alleviation and development. Liu et al. (2017) studied the differentiation mechanisms of rural poverty and confirmed that rational use of land resources helps eliminate poverty in poverty-stricken areas. Yan (2017) studied the role of land policy in poverty reduction and provided a reference for further development of practical land policies for poverty alleviation. Yao and Long (2016) investigated the relationship between graded land income and poverty alleviation, highlighting the need to formulate land-graded income distribution policies based on regional differences and to implement rational distribution of land-graded income to effectively alleviate poverty.

Altogether, studies on rural poverty have presented various new trends and characteristics in research methods, content, and perspectives (Zhang and Wan 2006; Glauben et al. 2012; Liu et al. 2016). Geography in particular has achieved fruitful results in the study of rural poverty based on refinement of census data, application of geographical information and remote sensing technologies, and development of spatial measurement (Jean et al. 2016). However, studies of land poverty alleviation and development are insufficient, and existing research continues to be dominated by qualitative analysis, lacking systematic and quantitative research based on regional differences. The academic advantages of spatial analysis require further investigation. At the same time, the main causes of poverty at the township scales are lack of spatial accurate identification and clear zoning, which directly affects the matching connection and accurate implementation of land poverty alleviation policies. The logical starting point for effective poverty alleviation is an accurate, scientific analysis of poverty-causing factors (Liu and Li 2017). Poverty issues usually have regional, phased, and dynamic characteristics (Wang et al. 2016a, 2016b; Zhou et al. 2018). Povertyreducing factors differ with region and stage of development, and poverty management strategies must also differ accordingly (Liu et al. 2016; Liu and Li 2017; Liu et al. 2017). One-size-fits-all poverty alleviation policies lead to inaccurate targeting of land development policies and uneven distribution of poverty alleviation resources, which diminishes the practical effectiveness and efficiency of land policies in poverty alleviation (Wang et al. 2016a, 2016b; Liu and Li 2017; Liu and Xu 2016). It also leads to a large regional difference in the effectiveness of poverty alleviation, and the overall poverty situation is still severe.

How to scientifically and accurately analysis the causes of poverty in township units, and then implement differentiated poverty alleviation and development according to local conditions, in order to achieve the goal of accurate implementation of land special assistance policies, is the key scientific problem to be solved in this study. In order to solve this key problem, the present study adopts the following structure: analysis of current poverty alleviation measures, diagnosis of bottlenecks, zoning of poverty-causing factors, and 

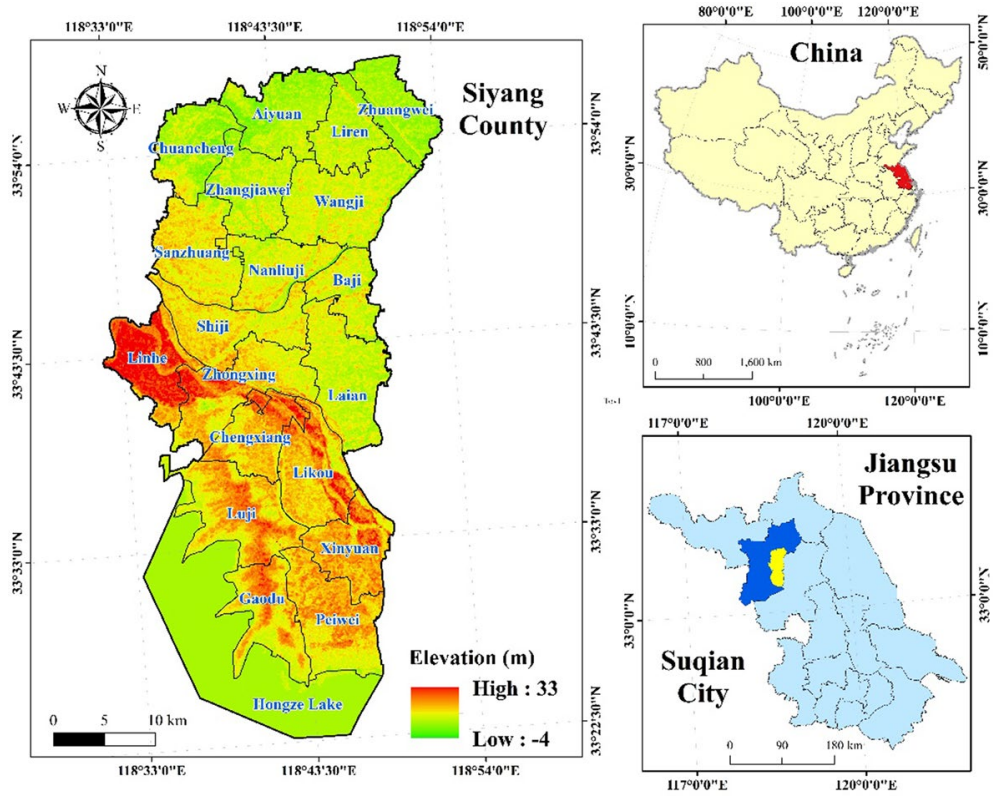

Fig. 1 Administrative division map of Siyang County, China

suggestion of poverty alleviation policies. By conducting field research in the case study site of Siyang County, Jiangsu Province, this study considers differentiation of povertycausing factors in various townships, including geographical environment, resource endowment, location conditions, labour structure, financial support, and technical level, and establishes corresponding relationships between each village's poverty status and the identified causes of poverty. The geographical detector model is applied to screen and select main causes of poverty, analyse and quantify spatial features, and propose precise poverty alleviation land policies for regions with different types of constraints. The research aims to change the current situation of the lack of targeted land policies and enrich the theoretical basis and empirical support of land policies to help poverty alleviation.

\section{Material and methods}

\subsection{Overview of research area}

As depicted inFig. 1, Siyang County, the research area of this study, is located in the Yellow River flood plain at about $118^{\circ} 20^{\prime}-118^{\circ} 45^{\prime}$ E and 33 $23^{\prime}-33^{\circ} 58^{\prime}$ N (Siyang County Statistical Yearbook 2016). As of 2016, Siyang County covers an area of $1418 \mathrm{~km}^{2}$ and has a population of 1.033 million. It has 11 towns, 5 townships, 3 subdistricts, 2 fields, and a provincial economic development zone (Siyang County Statistical Yearbook 2016). As the case area of this study, Siyang County is typical of the following: (1) as a plain agricultural county, Siyang's economic development foundation is weak. It is a traditional agricultural county with a cultivated land area of 1.06 million $m u$ ( $1 \mathrm{mu}$ is equivalent to $1 / 15$ hectares) 
and a basic farmland protection rate reaching $85 \% .^{1}$ The land resources available for development are very limited. (2) Siyang is a poor provincial county in Jiangsu Province and also is one of the 12 key targets identified in the 13th Five-Year Plan for poverty alleviation and development in Jiangsu Province (Jiangsu Province's 13th Five-Year Plan for Poverty Alleviation and Development in Rural Areas). As of 2016, the county has a total of 37,000 low-income ${ }^{2}$ households with a population of 121,200; 58 economically weak provincial villages; and two poverty alleviation and development zones: Lake Chengzi and the Lianshui-Shuyang-Siyang area. ${ }^{3}$ (3) Siyang County is a pilot area for poverty alleviation land policies linking new land used for urban construction with decrease in land used for rural construction. Under this pilot programme, surplus land supply quotas are transferred to Siyang County, which may circulate the surplus within the provincial region. The pilot area is expected to activate rural land for construction and to use the proceeds for compensation of resettled farmers, agriculture-related infrastructure construction, land remediation, and poverty alleviation and development. This programme is crucial for Siyang County to explore and establish urban construction funds to support new mechanisms of rural development. This kind of land poverty alleviation policy has a significant effect in Luji town. However, in other towns of Siyang County, the effect of poverty alleviation is not significant. The key bottleneck is the lack of differentiated screening of the main causes of poverty in poor towns, which directly affects the matching connection and precise implementation of land poverty alleviation policies. Based on the above three points, Siyang County is an ideal case area for the identification of the leading factors in rural poverty and the study of land poverty alleviation countermeasures.

\subsection{Data source}

This study uses field surveys to obtain the land poverty alleviation situation of Siyang County and typical townships and villages. Through seminars with the Siyang County Bureau of Land and Resources and the Poverty Alleviation Office, the data and information of the poverty situation in Siyang County, existing land poverty alleviation policies, and poverty alleviation results were obtained. Luji Towns, which demonstrated significant achievements in poverty alleviation, was selected to investigate the implementation and effectiveness of poverty alleviation policies. Through villager interviews and questionnaires, we grasped the achievements of typical townships and villages in terms of residents' living standards, infrastructure (road repairs, land conversion, water conservation, etc.), improvement of human settlements, and residents' views on the main causes of poverty in rural areas and existing land poverty alleviation policies. Socioeconomic statistics on the administrative villages used in this study were obtained from the Siyang County Statistical Yearbook 2016, provided by the Siyang County Statistical Bureau. The arable land area of each administrative village was calculated from the 2016 land use change data provided by the Siyang County Land and Resources Bureau. Data on the 2016 village-level poor population were provided by the Siyang County Poverty Alleviation Office. The selection of the cause of poverty was based on the results of the seminars and the survey questionnaire, and

\footnotetext{
1 The data were provided by Siyang County Land and Resources Bureau.

2 According to the 'Outline of Poverty Alleviation and Development in Rural Areas of China (20112020)', Siyang County has stipulated the standards for poverty and defined the farmers whose per capita annual income is less than CNY 6000 as poverty farmers.

3 The data were provided by Siyang County Poverty Alleviation Office.
} 


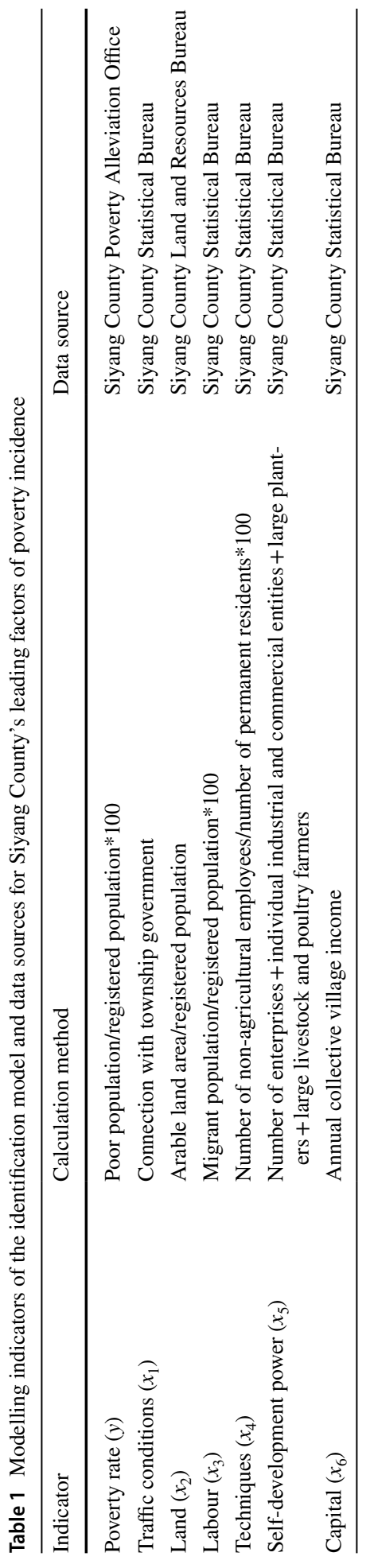


the existing research results of poverty were synthesised (Liu and Li 2017). The indicators, calculation methods, and data sources for modelling are shown in Table 1.

\subsection{Modelling method}

\subsubsection{Geographical detector model}

Poverty has prominent 'spatial attributes', and geographical study featuring long-term spatial analysis has an academic advantage in poverty research (Liu et al. 2016; Liu and Li 2017; Liu and Xu 2016). Therefore, this study chooses to use the geographical detector model. It is a statistical method for spatial heterogeneity. Its core idea is based on the assumption that if an independent variable has a significant impact on a dependent variable, the spatial distribution of the independent variable and the dependent variable should be similar (Wang and Xu 2017). The geographical detector model can test the spatial differentiation of single variable (differentiation and indicator detection) and also can detect the possible interaction between two variables (interaction detection) by checking the consistency of the spatial distribution of two variables. It is widely used in the analysis of the evolution of geographical element pattern and regional spatial differentiation.

Differentiation and indicator detection: It can detect the spatial differentiation of dependent variable $y$ and the extent to which the independent variable indicator $x_{\mathrm{i}}$ can explain the spatial differentiation of $y$. The influence degree of independent variable on dependent variable is measured by 'determination' indicator. This study introduces differentiated determining indicator of poverty incidence $(q)$ to detect the dominant factors in regional differentiation of rural poverty. The poverty incidence rate $y$ was collected within the study area and formed into a grid consisting of sampling units, $i(i=1,2, \ldots, n$, with $n$ being the total number of sampling units). $A=\left\{A_{h}\right\}$ is assumed to be a possible factor affecting poverty differentiation, where $h=1,2, \ldots, L ; L$ is a factor classification number; and $A_{h}$ represents different types of factor $A$. Each type $h$ corresponds to one or more spatial subregions. To detect the spatial correlation between factor $A$ and poverty incidence rate $y$, the layers of poverty incidence rate $y$ and factor $A$ are overlaid. For type $h$ of factor $A$ (corresponding to one or more subregions), the discrete variance of $y$ is denoted as $\sigma_{h}^{2}$, and the determination of factor $A$ on poverty incidence rate $y$ is calculated as follows:

$$
q=1-\left(1 / n \sigma^{2}\right) \sum_{h=1}^{L} n_{h} \sigma_{h}^{2},
$$

where $n_{h}$ is the number of samples within type $h$ of factor $A$ (corresponding to one or more subregions), $n$ is the total number of samples within the entire research area $H$, and $n=\sum_{h=1}^{L} n_{h} . L$ is the classification number of factor $A$ and $\sigma^{2}$ is the discrete variance of the overall region (Wang and $\mathrm{Xu} 2017$ ).

When each of the factors is able to determine poverty incidence, the discrete variance $\sigma_{h}^{2}$ of each type (corresponding to one or more subregions) is smaller, and the discrete variance between different types (corresponding to one or more subregions) is larger. When the discrete variance $\sigma_{h}^{2}$ approaches 0 , determination for factor $A$ is $q=1$. This is the ideal state, in which poverty differentiation is completely determined by factor $A$. When determination is $q=0$ for factor $A$, the poverty incidence rate is randomly distributed, and factor $A$ has no impact on poverty differentiation. A higher determination value $q$ indicates a greater 
influence of factor $A$ on the spatial differentiation of poverty (Wang and Xu 2017). This study detected six dominant factors in regional differentiation of rural poverty by comparing determination values: traffic conditions $\left(x_{1}\right)$, land resources $\left(x_{2}\right)$, labour $\left(x_{3}\right)$, techniques $\left(x_{4}\right)$, self-development power $\left(x_{5}\right)$, and capital $\left(x_{6}\right)$. Spatial detection and poverty incidence rate analysis were performed in each administrative village, and each factor's determination value $q$ was calculated.

Interaction detection: It can detect the degree of interaction between two independent variables on the dependent variable, and identify the interaction between different povertycausing indicators $\left(x_{\mathrm{i}}\right)$. In other words, it is independent to evaluate whether the independent variables $x_{1}$ and $x_{2}$ will increase or decrease the incidence of poverty when they work together, or whether these factors affect the incidence of poverty independently. The specific method is to calculate the determination value of two indicators $x_{1}$ and $x_{2}$ on the incidence of poverty: $q(\times 1 \cap \times 2)$. Then compare the relationship between $q(\times 1), q(\times 2)$ and $q(\times 1 \cap \times 2)$. The relationship can be divided into the following:

Nonlinear weakening: $q(\times 1 \cap \times 2)<\operatorname{Min}(q(\times 1), q(\times 2))$;

Single indicator nonlinear weakening: $\operatorname{Min}(q(\times 1), q(\times 2))<q(\times 1 \cap \times 2)<\operatorname{Max}(q(\times 1), q$ $(\times 2))$;

Two- indicators enhancement: $q(\times 1 \cap \times 2)>\operatorname{Max}(q(\times 1), q(\times 2))$;

Independent: $q(\times 1 \cap \times 2)=q(\times 1)+q(\times 2)$;

Nonlinear enhancement: $q(\times 1 \cap \times 2)>q(\times 1)+q(\times 2)$.

According to this, it can judge whether there is interaction between the two indicators, and whether the interaction is strong or weak, directional, linear, or nonlinear (Wang and $\mathrm{Xu}$ 2017).

\subsubsection{Hot spot analysis (Getis-Ord $G_{i}^{*}$ )}

The occurrence of poverty is always accompanied by a high degree of geographical proximity. Hot spot analysis is good at identifying the locations where high-value or low-value elements gather in space which can illustrates the spatial distribution of 'hot' and 'cold' spots (Tang 2012). The Getis-Ord $G_{i}^{*}$ formula is as follows:

$$
G_{i}^{*}(d)=\sum_{j=1}^{n} W_{i j}(d) X_{i} X_{j} / \sum_{j=1}^{n} X_{j}
$$

For easy explanation and comparison, $G_{i}^{*}(d)$ was standardised to eliminate the effects of fundamental units:

$$
Z\left(G_{i}^{*}\right)=G_{i}^{*}-E\left(G_{i}^{*}\right) / \sqrt{\operatorname{Var}\left(G_{i}^{*}\right)}
$$

where $E\left(G_{i}^{*}\right)$ is the mathematically expected value of $G_{i}^{*}, \operatorname{Var}\left(G_{i}^{*}\right)$ is the variance of $G_{i}^{*}$, and $W_{i j}(d)$ is the spatial weight. Weights were calculated in the same way as $G$ in Getis-Ord General. If $Z\left(G_{i}^{*}\right)>0$ and is significant, values around location $i$ are higher than average, and the location is thus situated in a high-value cluster (hot spot). If the opposite, values around location $i$ are lower than average, and the location is situated in a low-value cluster (cold spot) (Tang 2012). 


\section{Results}

\subsection{Description of seminars and survey questionnaires}

Since 2015, the land poverty alleviation policies promoted by Siyang County can be summarised as follows: (1) the land poverty alleviation policies linked with the increase in the urban construction land and the decrease in the rural construction land can solve the dilemma of lack of land for urban development and lack of money for rural revitalisation; (2) the construction of high-standard farmland promotes the development of modern agriculture and realises sustainable utilisation of land resources; (3) the implementation of displacement pilot project promotes the reduction process of construction land; (4) the comprehensive improvement of land promotes the adjustment of agricultural industrial structure and the increase in the production and employment of farmers. After the implementation of the above-mentioned land poverty alleviation policies, in 2016, the number of poverty farmers in Siyang County decreased by 19,700, and more than 6000 poverty farmers were employed. The collective economic income of 18 economically weak villages in the province exceeded CNY 180,000. It has accumulated 28,000 mu ( $1 \mathrm{mu}$ is equivalent to $1 / 15$ hectares) of cultivated land, 200,000 $\mathrm{mu}$ of new high-standard basic farmland, and 67,000 $\mathrm{mu}$ of new land circulation. A total of $1600 \mathrm{mu}$ of surplus indicators linked to increase and decrease was traded, and CNY 866 million was obtained.

Especially in Haoqiao Village (Luji Town), before 2015, there were 257 poor households and 956 poverty farmers. The per capita net income of farmers is CNY 906 lower than the county average. Through the implementation of comprehensive land improvement, Haoqiao Village has increased project employment and promoted employment nearby. In 2016, the per capita net income of farmers in the village increased to CNY 10,550. This study conducted random questionnaire surveys on the villagers. A total of 200 questionnaires were distributed and 200 valid questionnaires were recovered. The results show that $34.6 \%$ of the villagers surveyed are mainly from traditional farming, and $25 \%, 57 \%$, and $18 \%$ of the villagers believe that the main cause of poverty is lack of technology, capital, and labour, and $66 \%$ of the villagers think that the poverty alleviation effect of land remediation is significant.

\subsection{Spatial distribution of poverty incidence in Siyang County}

Siyang County and Luji town have made phased achievement in poverty alleviation through land poverty alleviation policies, but the overall situation of poverty alleviation in Siyang County is still complex and difficult. As of 2016, the county has a total of 37,000 low-income households with a population of 121,200, 58 economically weak provincial villages. The proportion of poverty farmer in some towns is still over $30 \%$ (Fig. 2). Poverty incidence in Siyang County is higher in the northern and western parts and lower in the southern and eastern parts; it is also higher in the peripheral regions than in the centre. Forty-four villages (17.60\% of all villages) had a poverty incidence rate of less than $7.96 \%$, 66 villages $(26.40 \%)$ had a poverty incidence rate within the range of [7.97, 12.64], and 100 villages $(40.00 \%)$ had a poverty incidence rate within the range of $[12.65,19.88]$.

The hot spot analysis was used to detect the spatial concentration areas of poverty incidence. The results show that the low-value poverty concentration areas are mainly distributed in the eastern half of Zhongxing Town, the northwest of Chengxiang Street and 
Fig. 2 Spatial distribution of poverty incidence in 2016 in Siyang County, China

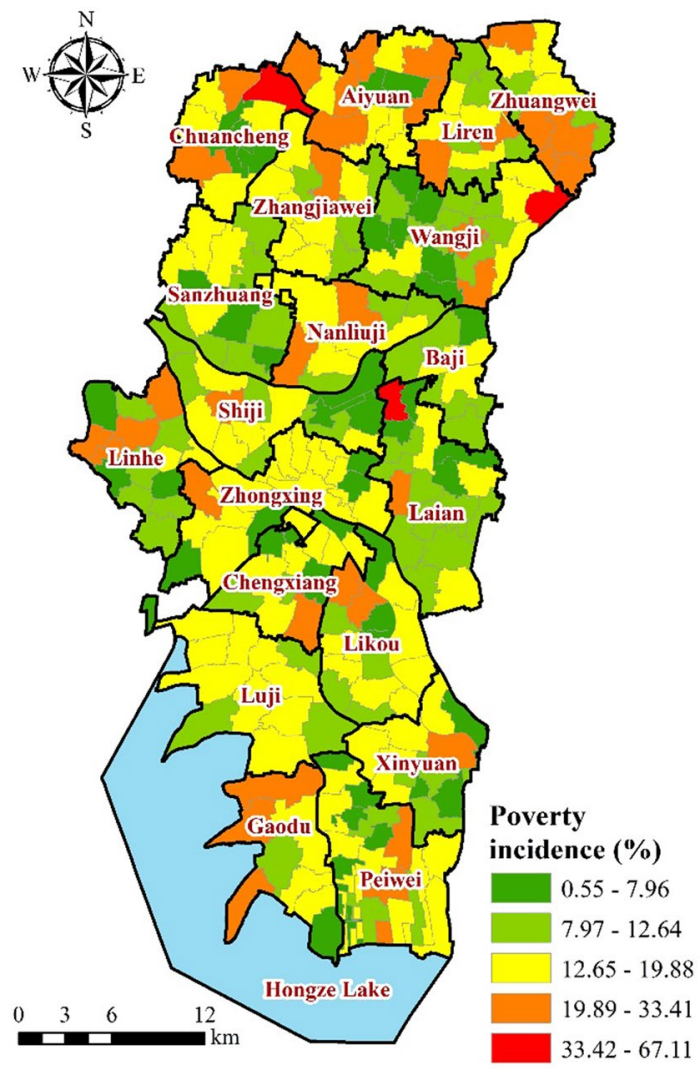

Luji Town, and some townships in Xinyuan Town. The high-value concentration areas of poverty incidence are located at the junctions of Aiyuan Town, Chuancheng Town, and Zhangjiawei Town, the junctions of Zhuangwei Town and Wangji Town, the west of Baji Town, and the northern half of Gaodu Town (Fig. 3).

\subsection{Spatial distribution of major poverty alleviation factors in Siyang County}

The determination values $q$ of traffic conditions $\left(x_{1}\right)$, land resources $\left(x_{2}\right)$, labour $\left(x_{3}\right)$, technology $\left(x_{4}\right)$, self-development power $\left(x_{5}\right)$, and capital $\left(x_{6}\right)$ on poverty incidence in Siyang County were $0.01,0.12,0.17,0.15,0.03$, and 0.14 , respectively (Fig. 4 ). This indicates that the main causes of poverty in Siyang County are lack of labour, technology, land resources, and financial support. As Siyang County is located in the Yellow River flood plain of Jiangsu Province, the overall economic foundation of Jiangsu Province is good, the industry and commerce is developed, the road network is dense, and the traffic infrastructure conditions are relatively perfect. Therefore, traffic conditions and self-development did not have a significant restrictive value on poverty in Siyang County.

Arable land is the material basis for development of agricultural production (Xie and Jiang 2016; Zhen et al. 2014; Li et al. 2015a, 2015b). The spatial distribution of per capita arable land in Siyang County is higher in the northern and southern regions than the central region. As shown in Fig. 5(a), Luji Town had the highest per capita arable land in 2016 
Fig. 3 Hot spot analysis of poverty incidence in Siyang County in 2016 (Getis-Ord $G_{i}^{*}$ )
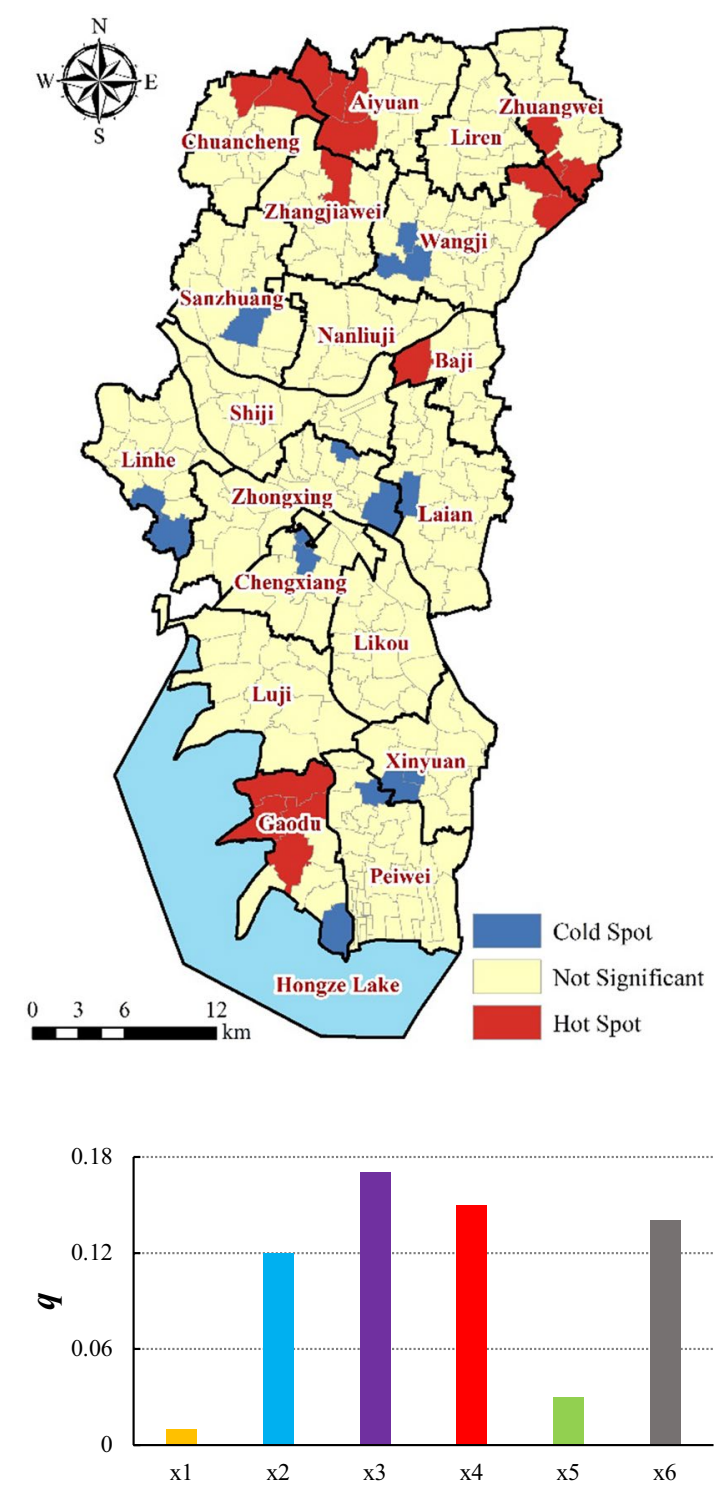

Fig. 4 Determination value $q$ of poverty alleviation factors on poverty incidence in 2016 in Siyang County, China

at $1087 \mathrm{~m}^{2} /$ person, with Guizui Village reaching $2338 \mathrm{~m}^{2} /$ person. Zhongxing Town had the lowest per capita arable land at only $573 \mathrm{~m}^{2} /$ person.

A large numbers of migrant workers have caused problems seriously restricting local economic development in rural communities, such as lack of labour and disused land (Chen et al. 2014; Qian et al. 2016; Du et al. 2005; Long et al. 2012). As shown in Fig. 5(b), villages with a high proportion of migrant workers as of 2016 are mainly distributed in Gaodu Town (11.04\%) and Peiwei Town (13.89\%) in the south, as well as Aiyuan Town (12.25\%) in the north. The proportions of migrant workers in Chenshi Village and Xinsi Community Neighbourhood Committee reached $43.14 \%$ and $44.62 \%$, respectively. 

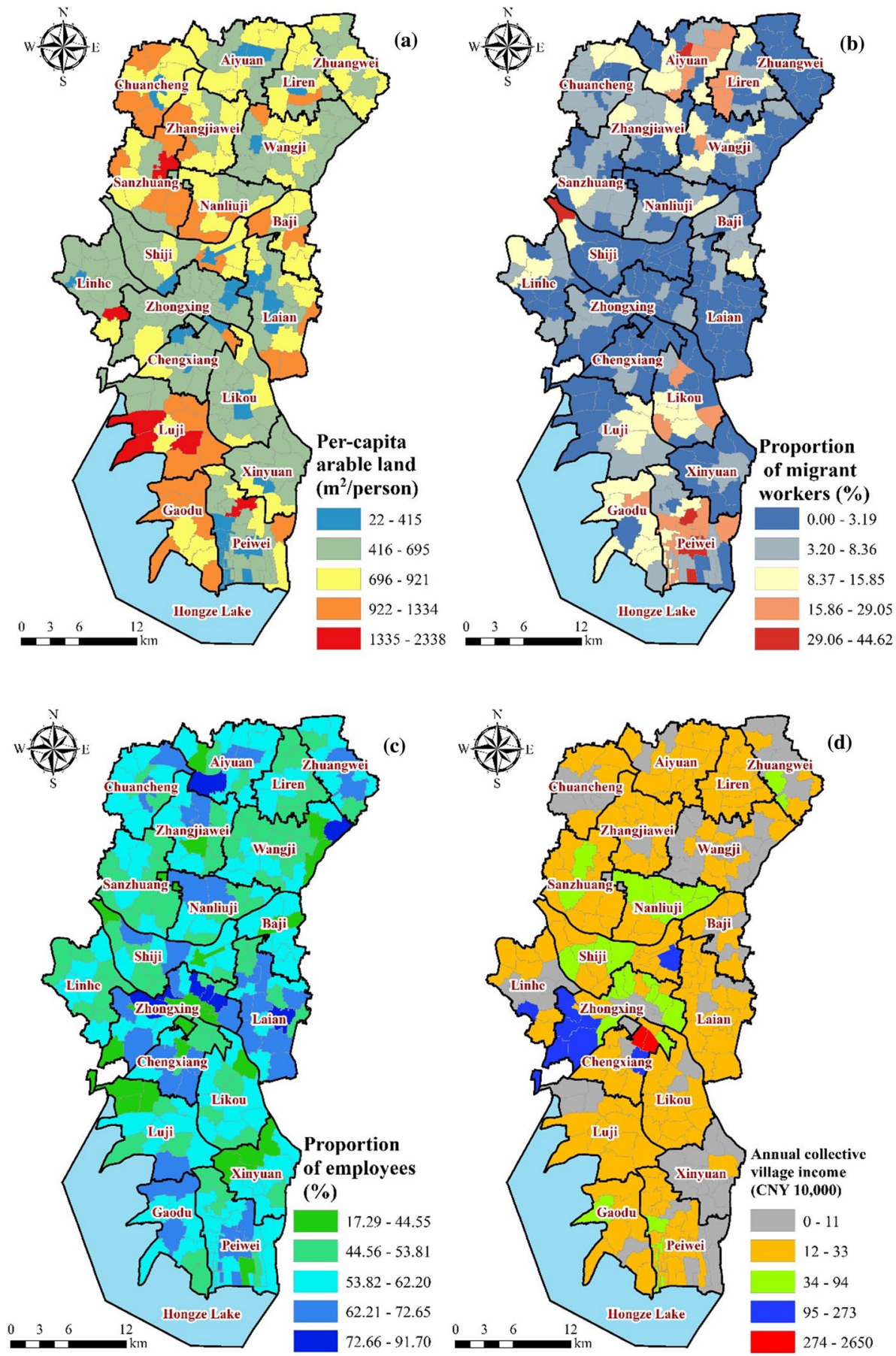

Fig. 5 Spatial distribution of poverty alleviation factors in 2016 in Siyang County, China: a arable land, b labour, $\mathbf{c}$ techniques, $\mathbf{d}$ capital 
Techniques are crucial for residents to engage in production and create value. The proportion of employees can reflect mastery of techniques in a region (Khan and Siddiqi 2011; Khan and Williams 2006; Bruton et al. 2013). As shown in Fig. 5(c), the townships with the highest proportion of employees in Siyang County in 2016 were Lai' an Subdistrict and Zhongxing Town. The number of employees in Liuwan Community Neighbourhood Committee and Qianjin Neighbourhood Committee, in particular, exceeded 6000.

Annual collective village income provides financial support for village development and improves village organisation and resident income level (Harrison et al. 2019; Aggarwal 2018; Asher and Novosad 2018). As shown in Fig. 5(d), the collective income of villages in Siyang County in 2016 was high in the central region and relatively low in the northern and southern regions. The First and Second Neighbourhood Committees of Zhongxing Town had the highest collective income at CNY 26.50 million and CNY 18.70 million, respectively. Donggao Neighbourhood Committee had the lowest collective income at only CNY 8000, illustrating a significant internal difference.

\subsection{Geospatial detection results for major poverty alleviation factors of townships}

Based on the spatial detection of causes of poverty in Siyang County, the geographical detector model was adopted to detect the causes of poverty in each township. According to the results, the townships of Siyang County were divided into four types: labour-constrained, arable land-constrained, technique-constrained, and capital-constrained (Fig. 6).

Six technique-constrained regions were identified, namely Peiwei Town (0.71), Xinyuan Town (0.69), Likou Town (0.62), Linhe Town (0.69), Zhangjiaxu Town (0.56), and Nanliuji Town (0.52); seven labour-constrained regions, namely Zhongxing Town (0.81), Chengxiang Subdistrict (0.77), Aiyuan Town (0.62), Wangji Town (0.23), Zhuangxu Town (0.74), Liren Town (0.68), and Baji Town (0.79); two arable land-constrained regions, namely Shiji Subdistrict (0.61) and Lai' an Subdistrict (0.71); and four capital-constrained regions, namely Chuancheng Town (0.68), Gaodu Town (0.55), Luji Town (0.80), and Sanzhuang Town (0.71).

The interaction detection results show that (Fig. 7), except the interaction between labour $\left(x_{3}\right)$ and capital $\left(x_{6}\right)$ is two-indicator enhancement, the interaction between any two factors is a nonlinear enhancement. It shows that the effect of any two indicators on the incidence of poverty is greater than the sum of the two indicators. Therefore, only by accurately identifying the main causes of poverty in each township and implementing targeted land poverty alleviation policies for the main causes of poverty can make the work of poverty alleviation play a maximum role and get twice the result with half the effort.

\section{Discussion}

\subsection{Necessity of precisely identifying causes of poverty}

Poverty alleviation land policies implemented in Siyang County have achieved significant results. However, because causes of poverty have not been precisely identified, poverty alleviation resources have been unevenly distributed, leading to significant regional differences in the effectiveness of poverty alleviation.

Since 2015, implementation of poverty alleviation policies in Siyang County has achieved win-win results. Modern and efficient agricultural models were adopted in 19 
Fig. 6 Regional types of poverty townships in Siyang County in 2016

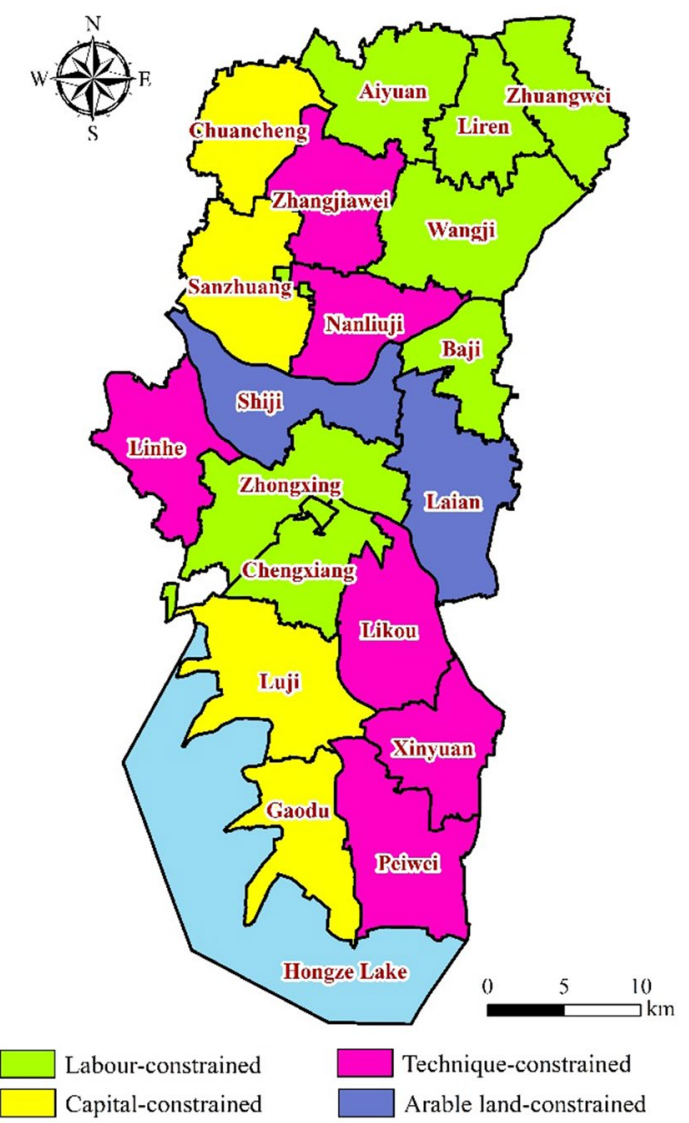

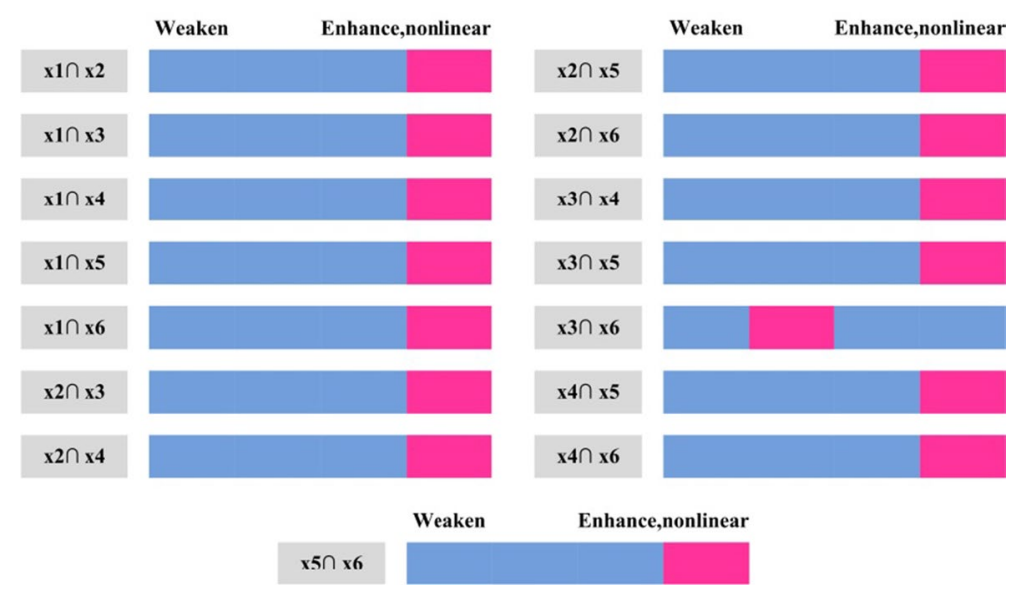

Fig. 7 Types of interaction detection of poverty indicators in Siyang County in 2016 
township areas within the county to strengthen the basic living infrastructure of rural production. This has eliminated poverty in poor areas and increased the per capita income of farmers in the county by CNY $1,100 .{ }^{4}$ For example, Haoqiao Village (Luji Town) has implemented a series of targeted poverty alleviation land projects in the past two years, reducing poverty incidence by $31.96 \% .^{5}$ The experience of Haoqiao Village serves as a valuable reference for underdeveloped rural areas.

However, the overall situation of poverty alleviation in Siyang County remains complex and challenging. As of 2016, 121,200 farmers still earned a low income ${ }^{6}$ in Siyang County. A total of $32.8 \%$ of villages had a poverty incidence rate of over $15 \%$. Furthermore, poverty incidence exceeded 30\% in eight villages, including Liuwan Village in Wangji Town and Yaowan Village in Chuancheng Town (Fig. 2). Poverty incidence was as high as $67.11 \%$ in Zhulou Village, Zhongxing Town. Results of the hot spot analysis (Fig. 3) show a significant spatial difference in poverty incidence among the towns and villages of Siyang County in 2016. Sixteen adjacent villages demonstrated high-value clustering in terms of poverty incidence. These villages form four hot spots in the northeast, northwest, southwest, and northwest central regions of Siyang County. Overall, poverty alleviation in Siyang County remains grim. At the same time, the strong interaction of poverty indicators in Siyang County also shows the importance and necessity of precise policy (Fig. 7). Only by implementing targeted land poverty alleviation policies for the main causes of poverty can make the work of poverty alleviation play a maximum role and get twice the result with half the effort.

The main reason for this phenomenon is the contradiction between variance in causes of poverty across township units and implementation of one-size-fits-all poverty alleviation land policies (Zhou et al. 2018; Wang et al. 2016a, 2016b). This contradiction leads to insufficient precision in land policies and inefficient allocation of poverty alleviation resources, seriously affecting the effectiveness of the policies (Liu et al. 2016; Liu and Li 2017). The main causes of poverty differ greatly among the townships of Siyang County. For example, the arable land resources of Luji Town are 2.21 times those of Zhongxing Town, and the collective income of Chengxiang Subdistrict is 64.87 times that of Xinyuan Town (Fig. 5). Thus, strategies for poverty management should also vary.

Existing studies do not precisely identify and clearly zone the main causes of poverty in township units. There is currently a lack of clear, differentiated, precise, and quantifiable spatial information to identify which townships are led to poverty because of capital constraints, labour constraints, land constraints, or technique constraints. This has led directly to large regional differences in the effectiveness of poverty alleviation in Siyang County, maintaining the overall grim situation of poverty in the county. Bottlenecks in poverty alleviation can be removed and land development policies enhanced by establishing the relationship between each township's situation and the main causes of poverty, screening and selecting the main causes of poverty and identifying and quantifying poverty with respect to spatial differences.

\footnotetext{
${ }^{4}$ The data were provided by Siyang County Land and Resources Bureau.

5 The data were provided by Siyang County Poverty Alleviation Office.

${ }^{6}$ Per capita annual income below CNY 6000.
} 


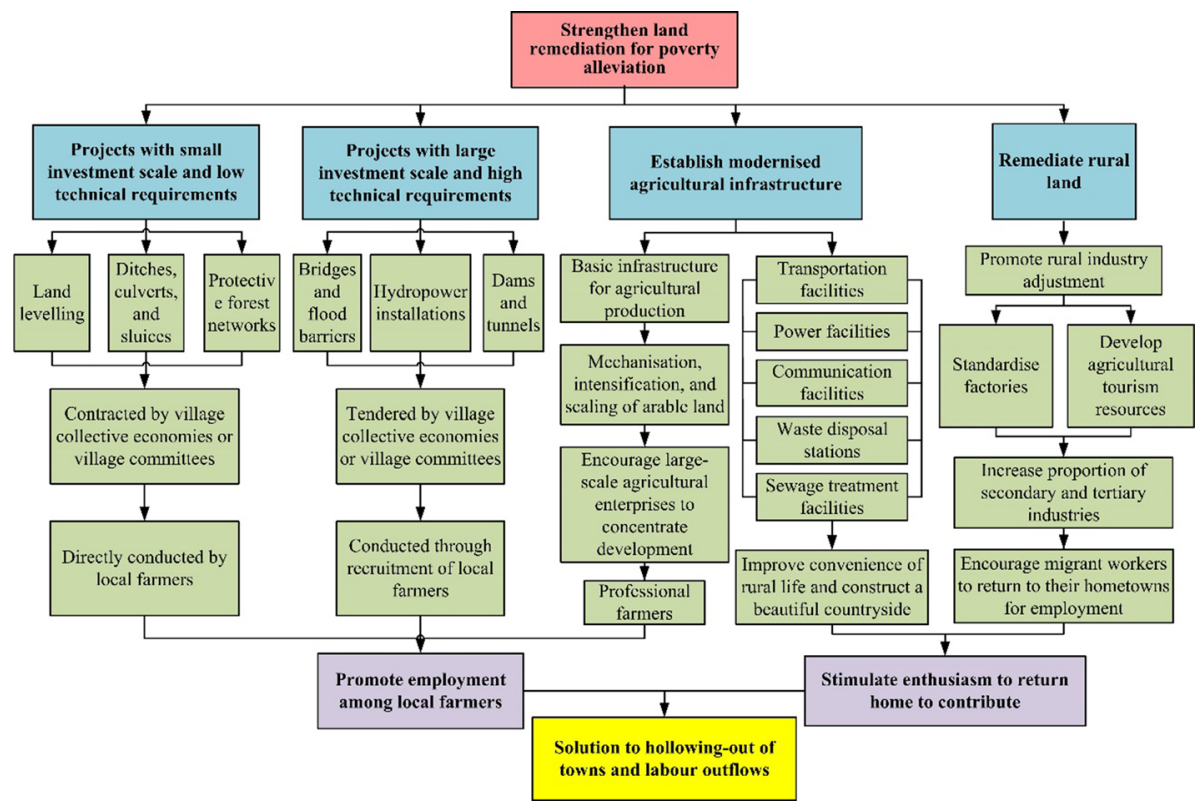

Fig. 8 Land poverty alleviation pattern in labour-constrained townships

\subsection{Implementation of land policies for townships with different types of poverty and improvement of land poverty alleviation efficiency}

To mitigate the bottlenecks caused by insufficient precise spatial information and lack of clear zoning of main causes of poverty in township units, the geographical detector model was adopted to diagnose and identify spatial differentiation characteristics and main poverty-causing factors in rural areas (Liu and Xu 2016; Liu and Li 2017). The present study thus clarifies the spatial zoning of different poverty-causing constraints, such as labour, land, capital, and techniques, and proposes specific poverty alleviation land policies for areas with different types of constraints.

Labour-constrained townships should focus on land remediation to increase employment in projects, promote local employment, improve rural liveability, and encourage people to return home to contribute (Fig. 8).

Land remediation to strengthen poverty alleviation and promote local employment. First, land remediation should be strengthened to support poverty alleviation, using construction projects to achieve growth in employment, especially promoting short-term employment of large numbers of farmers. Second, agriculture must be supported with modernised production infrastructure, creating conditions for the mechanisation and large-scale operation of arable land (Long 2014). Large-scale agricultural enterprises may be guided to concentrate on developing contiguous areas, hiring farmers to farm the land, forming professional agricultural groups, and creating long-term and stable employment opportunities. For example, the land improvement project in Siyang County provided 6000 jobs for villagers. Third, rural land for construction may be revitalised through land remediation. Light industries, such as agricultural product processing, could be developed in standardised factories, and agricultural tourism resources could also be developed into a service industry. This would expand secondary and 


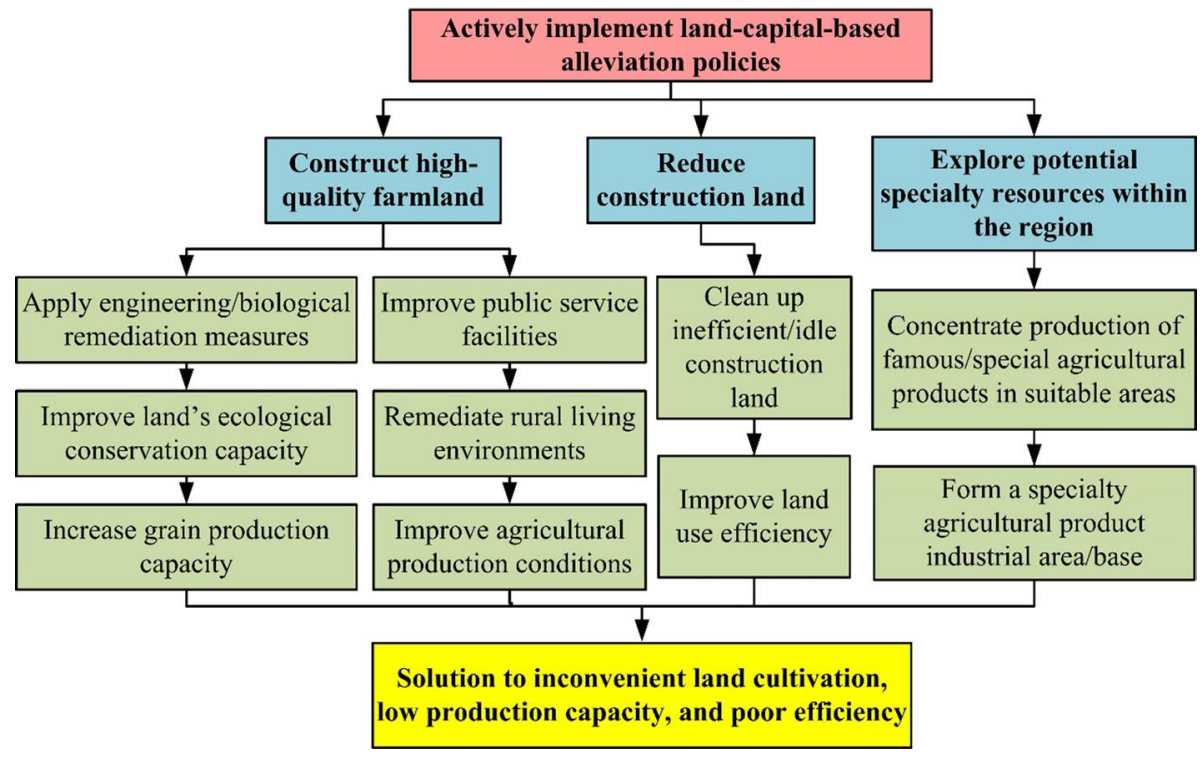

Fig. 9 Land poverty alleviation pattern in land-constrained townships

tertiary industries in rural areas and encourage migrant workers to return to their hometowns for employment (Ruan et al. 2013).

Planning of rural governance, construction of beautiful and liveable villages, and attraction of farmers back to their hometowns. First, the national land-use planning system can serve as a reference for rural spatial planning that features land remediation and integrates various essential elements of rural resources to optimise the allocation of rural production, livelihood, and ecological space. Second, the operability of rural spatial planning must be improved, considering the practical conditions of each township and conducting corresponding village construction designs. Rural infrastructure such as transportation, power, communications, sewage treatment, and waste disposal must be constructed to improve the convenience of rural life, promote village greening and beautification (Zhen et al. 2014), encourage farmers to return to their hometowns, and fundamentally alleviate poverty caused by labour constraints.

Land-constrained townships should adopt land-based poverty alleviation policies, such as balancing occupation and supplementation of arable land, and focus on protection and quality improvement of basic farmland (Fig. 9).

Accelerated construction of high-quality farmland and reduction in construction land; improvement of agricultural production conditions. To establish high-quality basic farmland infrastructure, construction of batches of high-quality farmland with drought and flood protection and stable, high-yield production must be accelerated. In 2016, Siyang County has accumulated 28,000 mu of cultivated land and 200,000 mu of new high-standard basic farmland. We must also improve the land's ecological conservation capacity, re-cultivate barren land, increase grain production capacity, and reduce ecological disasters and resulting returns to poverty. Rural communities may scientifically plan village renovation projects, improve public service facilities, improve production conditions and poor people's living environment, and expand income channels for farmers. In contrast, they may also revitalise construction land in stock, realise the 


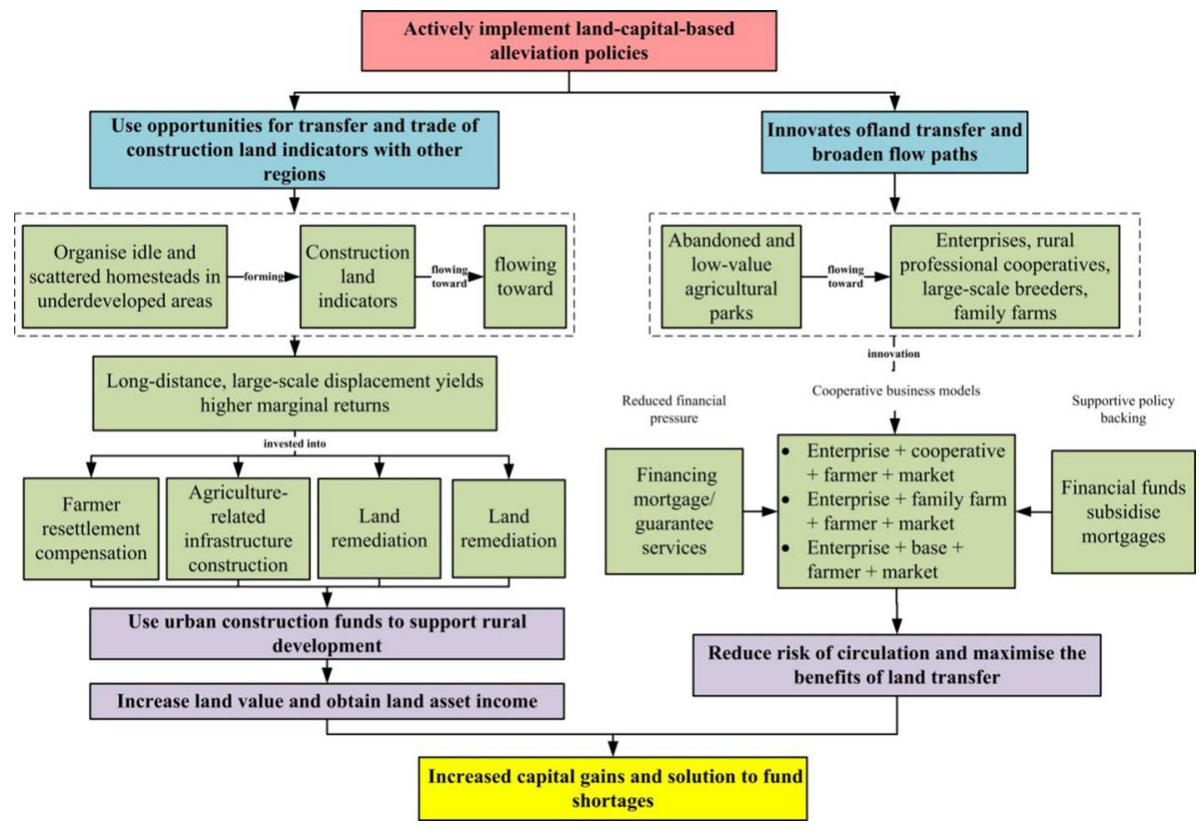

Fig. 10 Land poverty alleviation pattern in capital-constrained townships

utilisation potential of idle and inefficient construction land, and improve the efficiency of land resource utilisation (Yao and Long 2016).

Deepening of regional specialty resource potential and establishment of a specialty agricultural base. When planning specific land remediation projects, rural townships may fully tap the potential of regional specialty resources, guide concentrated production of famous and special agricultural products around suitable areas, and expand the production of various industrial zones for specialty agricultural products to show strong competitiveness. In particular, they must support high participation of the poor population in constructing a series of specialty agricultural bases (Long et al. 2016a, 2016b; Ruan et al. 2013), allowing those in poverty to share the value-added income from the agricultural industry and value chains.

Capital-constrained townships should make use of opportunities for transfer and trade of construction land indicators with other regions and focus on accumulating capital gain through land transfers and land use policies, such as the programme linking new land used for urban construction with decrease in land used for rural construction (Fig. 10).

Use of opportunities for transfer and trade of construction land indicators with other regions to accumulate capital for development. A cross-regional transfer policy linking new land used for urban construction with decrease in land used for rural construction, as well as the higher marginal returns yielded from long-distance, large-scale displacement, will increase the value of land in rural areas, especially those that are remote, and bring asset benefits to farmers in poverty-stricken areas (Yan 2017). In 2016, Siyang County obtained a total of CNY 866 million by transaction $1600 \mathrm{mu}$ of surplus indicators linked to increase and decrease. Poor townships should take advantage of opportunities for transfer and trade, strive for an annual increase in the 'linked increase and decrease' programme, 


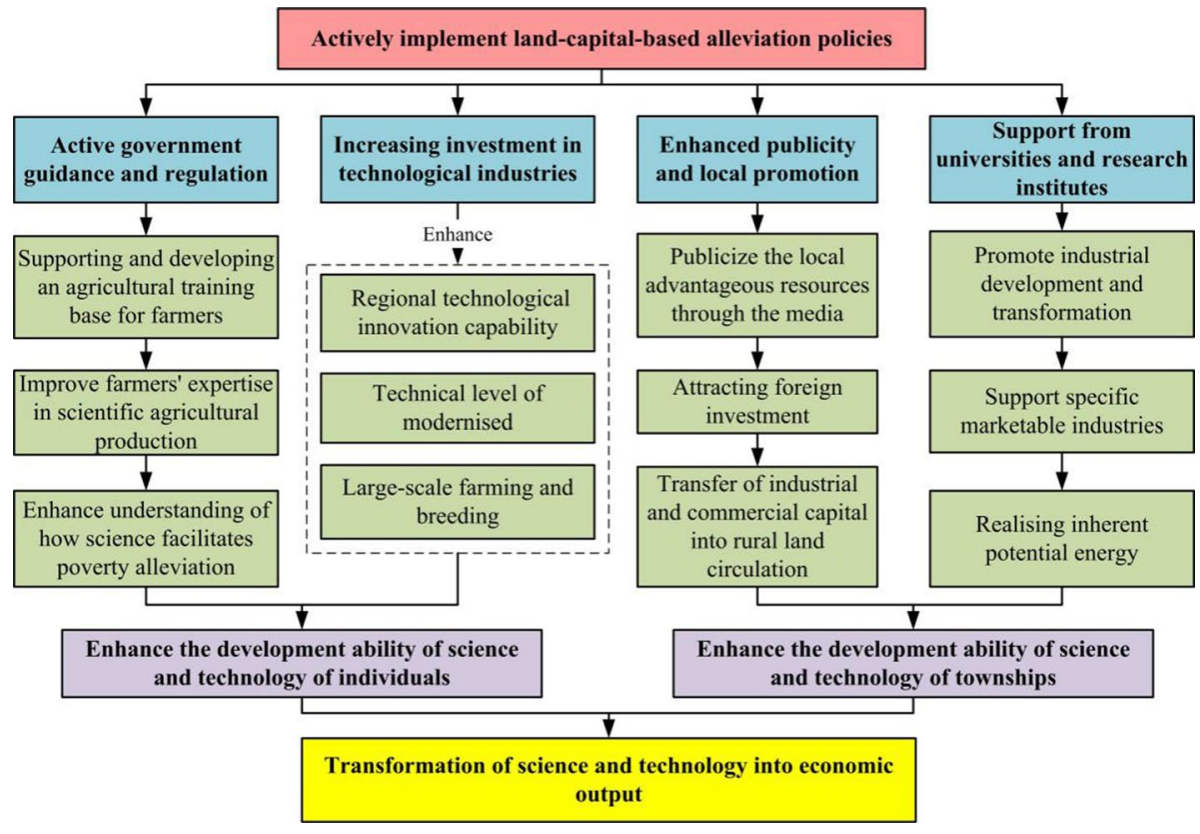

Fig. 11 Land poverty alleviation pattern in technique-constrained townships

deepen cooperation and matching ability with counterpart cities and counties, and maximise the benefits of surplus index transactions.

Innovative forms of land transfer and broadened land circulation path. Communities should be encouraged to disperse, transferring idle, abandoned, and low-value agricultural parks to enterprises, cooperatives, and large-scale breeders. Communities may also explore and establish a variety of cooperative business models, allowing farmers to transfer land via shareholding and receive dividends at the end of the year as shareholders (Liu 2016; Ruan et al. 2013). Supportive policies, such as financial subsidies and mortgage loans, should be encouraged. Additionally, financial assessment and guarantee institutions could provide services for financial mortgages of economic organisations within the county, such as enterprises, cooperatives, and large-scale breeders, to reduce financial pressure to aid their development and reduce risk of circulation.

Technique-constrained townships should strengthen their inherent self-development powers; enhance endowment of townships and individuals; maximise the functions of government guidance, regulation, and promotion; and rely on the technological advantages of scientific research institutes to facilitate land-based poverty alleviation policies supported by science and technology as a powerful force for regional resource integration (Fig. 11).

Active government guidance and regulation. The government should actively engage in guidance and regulation, simultaneously supporting and developing an agricultural training base for farmers. Training must consider the practical circumstances of different areas of poverty, and hold differentiated training courses accordingly (Bruton et al. 2013). Organised courses on poverty alleviation fund management and leadership will allow both organisations and poor people in poverty-stricken areas to enhance their understanding of how science facilitates poverty alleviation and their expertise in scientific agricultural production. 
Support from universities and research institutes. By maximising the role of universities and research institutes and building an industrial platform, the county can promote development and transformation and support specific marketable industries in poverty-stricken areas, realising their inherent potential energy.

Enhanced publicity and local promotion. By strengthening publicity and guidance on the official county website, local TV stations, and other media, the county can proactively promote superior local resources, increase foreign investment, and attract industrial and commercial capital into rural land circulation.

Moreover, by increasing investment in technological industries, the county may enhance regional technological innovation capability and the technical level of modernised, largescale farming and breeding, promoting economic growth in poverty-stricken areas and continuously increasing the income of the poor population.

\section{Conclusion}

On the basis of field investigation and geographical detector, this study has realised a systematic research of the identification of major poverty-causing factors, the regional division of poverty types, and the summary of land poverty alleviation policy patterns in Siyang County. As a result, the dominant factors affecting differentiation of rural poverty in Siyang County are labour, technology, land resources, and financial support. The various townships of the county were thus classified into four types according to the main factor affecting poverty: labour-constrained, land-constrained, capital-constrained, and techniqueconstrained, and proposes precise, targeted poverty alleviation land policies for areas with different types of constraints. Overall, the results can be summarised as 'four dominant factors of poverty - four regional types of poverty townships-four targeted land poverty alleviation patterns'. Detailed results are presented below.

Land poverty alleviation policies in Siyang County have made outstanding achievements. The research results confirm that land remediation has significant external spillover effects, which can produce good economic, social, and ecological benefits, and has unique advantages in promoting poverty alleviation and development. Land remediation by increasing the endowment of land resources in poor areas creates conditions for expanding production, thus increasing the productive income of farmers. At the same time, through the combination of land system and policy innovation, the market mechanism and capital operation mode are introduced into the countryside to promote the integration and reconstruction of multiple elements such as land, labour, technology, and capital, so as to increase the property income of farmers.

But these must be based on scientific analysis of the causes of poverty. Because the poverty alleviation needs of township units have not been precisely identified, one-sizefits-all land policies are unable to effectively allocate poverty alleviation resources. Consequently, the actual efficiency of policies has been severely restricted, leading to regional differences in poverty alleviation. In response to this bottleneck, the present study used the geographical detector model to precisely detect the core factors leading to poverty in administrative units at all levels. The results showed that the dominant factors affecting differentiation of rural poverty in Siyang County are labour, techniques, land, and capital. The various townships of the county were thus classified into four types according to the main factor affecting poverty: labour-constrained, land-constrained, capital-constrained, and technique-constrained. 
Finally, to address the key poverty elimination constraints of different types of townships, precise land poverty alleviation patterns must be implemented. Labour-constrained townships should rely on land remediation to increase project employment, promote local employment, improve rural liveability, and encourage residents to return to their hometown. Land-constrained townships should maximise land-based poverty alleviation policies, such as the balance of arable land and compensation, to protect and improve the quality of basic farmland. Capital-constrained townships should take advantage of opportunities for trade and transfer of construction land indicators with other regions to increase capital gain. Technique-constrained townships should strengthen their inherent self-development power, enhance township and individual factor endowments, and maximise government guidance, regulation, and promotion. With the technological advantages of scientific research institutes, poverty alleviation land policies supported by science and technology have become powerful forces for regional resource integration.

Open Access This article is licensed under a Creative Commons Attribution 4.0 International License, which permits use, sharing, adaptation, distribution and reproduction in any medium or format, as long as you give appropriate credit to the original author(s) and the source, provide a link to the Creative Commons licence, and indicate if changes were made. The images or other third party material in this article are included in the article's Creative Commons licence, unless indicated otherwise in a credit line to the material. If material is not included in the article's Creative Commons licence and your intended use is not permitted by statutory regulation or exceeds the permitted use, you will need to obtain permission directly from the copyright holder. To view a copy of this licence, visit http://creativecommons.org/licenses/by/4.0/.

\section{References}

Aggarwal, S. (2018). Do rural roads create pathways out of poverty? Evidence from India. Journal of Development Economics, 133, 375-395.

Asher, S. E., \& Novosad, P. (2018). Rural roads and local economic development. Washington, DC: World Bank.

Berger, L., Cancian, M., \& Magnuson, K. (2018). Anti-poverty policy innovations: New proposals for addressing poverty in the United States. RSF: The Russell Sage Foundation Journal of the Social Sciences, 4(3), 1-19.

Besley, T., \& Burgess, R. (2000). Land reform, poverty reduction, and growth: Evidence from India. Quarterly Journal of Economics, 115(2), 389-430.

Bi, Y., Gou, T., Zhang, Q., \& Hu, X. (2012). The study on coordinated development between urban and rural areas of Germany and its implications for China: The case of the state of Bavaria. Ecological Economy, 5, 99-102.

Bruton, G., Ketchen, D., \& Ireland, R. (2013). Entrepreneurship as a solution to poverty. Journal of Business Venturing, 28(6), 683-689.

Carr, S., Thompson, M., Dalal, A., De Guzman, J., Gloss, A., Munns, L., et al. (2014). Psychology and poverty reduction: A global special issue. International Perspectives in Psychology: Research, Practice, Consultation, 3(4), 215-237.

Chen, R., Ye, C., Cai, Y., Xing, X., \& Chen, Q. (2014). The impact of rural out-migration on land use transition in China: Past, present and trend. Land Use Policy, 40, 101-110.

Dong, X. (2004). Two-tier land tenure system and sustained economic growth in post-1978 rural China. World Development, 24(5), 915-928.

Du, Y., Park, A., \& Wang, S. (2005). Migration and rural poverty in China. Journal of Comparative Economics, 33(4), 688-709.

Glauben, T., Herzfeld, T., Rozelle, S., \& Wang, X. (2012). Persistent poverty in rural China: Where, why, and how to escape? World Development (Oxford), 40(4), 784-795.

Gobillon, L., Selod, H. (2014). Spatial mismatch, poverty, and vulnerable populations. In Handbook of Regional Science, (chapter 7, pp. 93-107). https://doi.org/10.1007/978-3-642-23430-9. 
Gourvish, T., \& Fraser, D. (1973). The evolution of the British welfare state. Economic History Review, 27(1), 543-544.

Harrison, J., Montgomery, C., \& Jeanty, P. (2019). A spatial, simultaneous model of social capital and poverty. Journal of Behavioral and Experimental Economics, 78, 183-192.

Haushofer, J., \& Fehr, E. (2014). On the psychology of poverty. Science, 344(6186), 862-867.

Iari, I. (1970). Green revolution in India. Annals of the Association of American Geographers, 63(3), 319-330.

Jean, N., Burke, M., Xie, M., Davis, W., Lobell, D., \& Ermon, S. (2016). Combining satellite imagery and machine learning to predict poverty. Science, 353(6301), 790-794.

Kelly, M., \& Gráda, C. (2010). The poor law of old England institutional innovation and demographic regimes (1). Journal of Interdisciplinary History, 41(3), 339-366.

Khan, H., \& Williams, J. (2006). Poverty alleviation through access to education: Can e-learning deliver? New York: Social Science Electronic Publishing.

Khan, K., \& Siddiqi, M. (2011). Role of light engineering sector in poverty reduction amongst its employees: A case study of Gujranwala, Gujrat and Sialkot Districts. Interdisciplinary Journal of Contemporary Research in Business, 3(1), 1432.

Li, Y., Li, Y., Westlund, H., \& Liu, Y. (2015a). Urban-rural transformation in relation to cultivated land conversion in China: implications for optimizing land use and balanced regional development. Land Use Policy, 47, 218-224.

Li, Y., Long, H., \& Liu, Y. (2015b). Spatio-temporal pattern of China's rural development: A rurality index perspective. Journal of Rural Studies, 38, 12-26.

Li, Y., Wu, W., Song, C., \& Liu, Y. (2019). Spatial-temporal pattern of world poverty reduction and key problems analysis. Bulletin of Chinese Academy of Sciences, 34(1), 42-50.

Liao, R., \& Du, G. (2014). Development of land consolidation in the Netherlands and its implications for China. China Land Resources and Economy, 17(9), 26-28.

Liu, W. (2016). How to promote poverty alleviation by land consolidation. China Land, 4, 35-37.

Liu, Y., Chen, C., \& Li, Y. (2015). Differentiation regularity of urban-rural equalized development at prefecture-level city in China. Journal of Geographical Sciences, 25(9), 1075-1088.

Liu, Y., \& Li, J. (2017). Geographic detection and optimizing decision of the differentiation mechanism of rural poverty in China. Acta Geographica Sinica, 70(1), 161-173.

Liu, Y., \& Li, Y. (2017). Revitalize the world's countryside. Nature, 548, 275-277.

Liu, Y., Liu, J., \& Zhou, Y. (2017). Spatio-temporal patterns of rural poverty in China and targeted poverty alleviation strategies. Journal of Rural Studies, 52, 66-75.

Liu, Y., \& Xu, Y. (2016). A geographic identification of multidimensional poverty in rural China under the framework of sustainable livelihoods analysis. Applied Geography, 73, 62-76.

Liu, Y., Zhou, Y., \& Liu, J. (2016). Regional differentiation characteristics of rural poverty and targeted poverty alleviation strategy in China. Bulletin of Chinese Academy of Sciences, 31(3), 269-278.

Long, H. (2014). Land consolidation: An indispensable way of spatial restructuring in rural China. Journal of Geographical Sciences, 24(2), 211-225.

Long, H., Li, Y., Liu, Y., Woods, M., \& Zou, J. (2012). Accelerated restructuring in rural China fueled by 'increasing vs. decreasing balance' land-use policy for dealing with hollowed villages. Land Use Policy, 29(1), 11-22.

Long, H., Tu, S., \& Ge, D. (2016a). Effects of new-type urbanization on poverty alleviation and development and corresponding countermeasures. Bulletin of Chinese Academy of Sciences, 31(3), 309-319.

Long, H., Tu, S., Ge, D., Li, T., \& Liu, Y. (2016b). The allocation and management of critical resources in rural China under restructuring: Problems and prospects. Journal of Rural Studies, 47(47), 392-412.

Long, H., Zou, J., \& Liu, Y. (2009). Differentiation of rural development driven by industrialization and urbanization in eastern coastal China. Habitat International, 33(4), 454-462.

Mani, A., Mullainathan, S., Shafir, E., \& Zhao, J. (2013). Poverty impedes cognitive function. Science, 341(6149), 976-980.

National Statistical Bureau of the People's Republic of China. (2018). Statistical bulletin of the People's Republic of China on national economic and social development in 2017. China Statistics, 3.

North, D. (1955). Location theory and regional economic growth. Journal of Political Economy, 63(3), 243-243.

Qian, W., Wang, D., \& Zheng, L. (2016). The impact of migration on agricultural restructuring: Evidence from Jiangxi Province in China. Journal of Rural Studies, 47, 542-551.

Ruan, S., Wu, K., \& Zheng, Z. (2013). Chinese system and policy of land poverty alleviation. Scientific and Technological Management of Land and Resources, 30(5), 115-121.

Sen, A. (1999). Development as Freedom. Oxford: Oxford University Press. 
Shepherd, A. (2010). Growth and poverty reduction: Policy implications from qualitative research in Tanzania. SSRN Electronic Journal, 2(4), 381-383.

Siyang County Statistical Yearbook. (2016). Siyang Statistical Bureau.

Tang, G. (2012). ArcGIS experimental tutorial on spatial analysis of geographic information systems. Beijing: Science Press.

Wang, J., Chen, Y., \& Yan, M. (2016a). Research on the targeted measures of poverty alleviation and its innovative ways in China. Bulletin of Chinese Academy of Sciences, 31(3), 289-295.

Wang, J., \& Xu, C. (2017). Geographical detector: Principle and prospective. Acta Geographica Sinica, $72(1), 116-134$.

Wang, Y., Liu, Y., Li, Y., \& Li, T. (2016b). The spatio-temporal patterns of urban-rural development transformation in China since 1990. Habitat International, 53, 178-187.

Wu, Z., Liu, M., \& Davis, J. (2005). Land consolidation and productivity in Chinese household crop production. China Economic Review, 16(1), 28-49.

Xie, Y., \& Jiang, Q. (2016). Land arrangements for rural-urban migrant workers in China: Findings from Jiangsu Province. Land Use Policy, 50, 262-267.

Yan, J. (2017). Analysis of the mechanism and effect of land policy in poverty alleviation. China Land, 11, $14-17$.

Yao, S., \& Long, T. (2016). Policy innovation of urban-rural construction land increasing or decreasing balance based on the targeted poverty alleviation. Journal of Southwest University for Nationalities, $37(11), 124-129$.

Yue, Y., \& He, L. (2016). A note of academic history about accurate poverty alleviation: Sen's poverty concept. Economic Issue, 12, 17-20.

Zang, Y., Liu, Y., Yang, Y., \& Wang, Y. (2019). Typical models of land consolidation for poverty alleviation. Geographical Research, 38(4), 856-868.

Zhang, Y., \& Wan, G. (2006). The impact of growth and inequality on rural poverty in China. Journal of Comparative Economics, 34(4), 694-712.

Zhen, N., Fu, B., Lü, Y., \& Zheng, Z. (2014). Changes of livelihood due to land use shifts: A case study of Yanchang county in the loess plateau of China. Land Use Policy, 40, 28-35.

Zhou, Y., Guo, Y., Liu, Y., Wu, W., \& Li, Y. (2018). Targeted poverty alleviation and land policy innovation: Some practice and policy implications from China. Land Use Policy, 74, 53-65.

Publisher's Note Springer Nature remains neutral with regard to jurisdictional claims in published maps and institutional affiliations.

\section{Affiliations}

\section{Min $\operatorname{Min}^{1,2} \cdot$ Chen Lin ${ }^{1} \cdot$ Xuejun Duan ${ }^{1} \cdot$ Zhifeng Jin $^{3,4} \cdot$ Luocheng Zhang ${ }^{1}$}

1 Key Laboratory of Watershed Geographic Sciences, Nanjing Institute of Geography and Limnology, Chinese Academy of Sciences, 73 East Beijing Road, Nanjing City 210008, P. R. China

2 University of Chinese Academy of Sciences, Beijing 100049, China

3 School of Resource and Environmental Sciences, Wuhan University, Wuhan 430072, China

4 Jiangsu Research Center of Land and Resources, Nanjing 210017, China 